\title{
On Transformation of Land Finance from the Perspective of Local Economic Growth-System GMM Analysis Based on Dynamic Panel Data of Prefectural Cities
}

\author{
Xinyang Zhang \\ School of Materials Science and Engineering, University of Jinan, Jinan, China \\ Email address: \\ 1136810269@qq.com \\ To cite this article: \\ Xinyang Zhang. On Transformation of Land Finance from the Perspective of Local Economic Growth-System GMM Analysis Based on \\ Dynamic Panel Data of Prefectural Cities. International Journal of Economics, Finance and Management Sciences. \\ Vol. 7, No. 1, 2019, pp. 6-12. doi: 10.11648/j.ijefm.20190701.12
}

Received: December 15, 2018; Accepted: January 28, 2019; Published: February 1, 2019

\begin{abstract}
Based on the panel data of 265 prefecture-level cities in China, the dynamic panel model system (GMM) was used to estimate the relationship between local economic growth and land finance. The results of the study indicate that local economic growth is largely influenced by land finances. From the perspective of sub-regions, the impact of land finance on local economic growth in different regions is significantly different, having more influence on the economic growth in the central and western regions than the eastern regions. In the current environment of economic development, land finance has its own significance, and its role in promoting local economic development, especially in the central and western regions, cannot be underestimated. The local government should transform the land finance from the three aspects of land fiscal revenue, expenditure and the transformation of local government functions, in order to alleviate the current adverse impact of land finance on economical and social development.
\end{abstract}

Keywords: Land Finance, Dynamic Panel, System GMM, Economic Growth

\section{Introduction}

Since 2003, with the increasing proportion of land transfer funds in local fiscal revenue, local governments have increasingly relied on land finance, as a result, land finance has gradually become the most concerned issue in China's fiscal system. According to the calculation of the National Bureau of Statistics, in 2011, the country's land sales revenue was 3.15 trillion yuan, in 2014, it was 4.26 trillion yuan, and in 2017 it reached an all-time high of 5 trillion yuan. From a nationwide perspective, revenue from land transfer accounts for more than $60 \%$ of the local fiscal budget. In some areas, land transfer revenue equals or even exceeds fiscal revenue within the budget. Land finance has become the "second fiscal" of the local government.

The growing land finance has had a profound impact on China's economy and society. The academic community generally believes that land finance has both positive and negative effects on the economy and society. According to previous studies, the social focus on land finance has been more focused on its negative effects. Scholars firmly hold that consequences of rise of housing prices, local debt risks and macroeconomic fluctuations, land violations and corruption shall be attributed to land finance, while these economic negative effects do not lead to the disappearance of land finance. In this context, this paper believes that society should have a more rational understanding and analysis of land finance, perhaps there is an inevitable cause for the emergence and existence of land finance. Although the land finance has produced a lot of adverse effects on the economy of China, its important role to national economy of China cannot be easily overestimated. At present, China has entered a new normal economy and its overall economic growth has slowed down. At the same time, according to the understanding of industrial optimization and transformation, China is still in the stage of promoting urbanization as its key objective. In the coming period, it is believed that land finance will promote urbanization development. The nature of scarce land resources, of course, determines that the model of relying on land sales income to obtain fiscal revenue is not sustainable. However, 
under the constraints of the current system, "land finance" cannot be replaced, and it has a positive impact on urbanization and economic growth. It does not mean that China should adopt a completely negative and complete cancellation attitude because of the disadvantages of land finance itself, however, it is also essential to promote its transformation.

\section{Literature Review and Influence Mechanism}

Under the appraisal system of fiscal decentralization, land dualism, and local government performance based on economic growth and fiscal revenue, they formed land finance through synergy [1]. The emergence of land finance has timely improved the current situation in which local governments need to change their taxation rights after the reform of the tax sharing system. This has cleared the way for further economic development. The emergence of land finance was not only related to China's current fiscal system, and also, one of its necessary conditions shall be attributed to China's highly distinctive land system [2]. At present, throughout the literature on land finance and economic growth, most of the focus is on the analysis of the dual functions of land finance. The first is the function of public finances, that is, to get access to land financing by the transfer of the right to use state-owned land and the exchange of land for bank mortgage loan, in order to improve basic service facilities and provide public services in cities. The second is production finance function, to promote local attraction investment by implementation of industrial land price reduction, preferential tax policies and vigorously supporting industrial facilities, so as to promote tax growth and increase the total amount of economy [3-8].

In recent years, a large number of studies on land finance have emerged in the academic community. The discussion of existing literature on the emergence and existence of land finance is mainly reflected in two aspects: first of all, some scholars believe that the land finance stems from "fiscal pressure", that is, the implementation of reform of tax sharing system in 1994 caused mismatch between central and local power of affairs and financial power, the right of fiscal revenue of local governments was shifted upward and the right of fiscal expenditure was decentralized, transfer payment of superior government were unable to meet the rigid demand of local government expenditure, as a result, they aimed at the land market that they could control to get huge amount of land transfer fund to make up for the deficit [9]. In addition, there are also scholars who believe that land finance originates from the "investment impulse" of local governments. Under the performance evaluation system with GDP as the core in China, local government officials have to transfer large amounts of land in order to obtain huge amounts of land fiscal revenue to invest in infrastructures in order to win the Promotion Tournament, this excessive investment by local governments has led to a surge in local GDP, and the increase in GDP has made it easier to create incentives for government officials, which has further stimulated the increase in local investment. This ratchet effect has greatly promoted regional economic growth [10].

The impact mechanism of land finance on local economic growth can also be analyzed from the above two aspects. On the one hand, the public function caused by "fiscal pressure" promotes economic growth. Gradual taxation reforms have increased the proportion of central government revenue to the country's fiscal revenue, but have not correspondingly reduced the proportion of local government fiscal expenditures to national fiscal expenditure. Local governments are "forced" to increase extra budgetary fees and non-budgetary management funds to seek new ways to get revenue [11]. At the same time, the amendments to the "Constitution" and the "Land Management Law" have led local governments to get actual monopoly positions in the primary market of urban land. Local governments that have monopoly power in the primary market of the land naturally choose land as business project for city economic development. As a result, land finance has gradually become an important source of capital for urban infrastructure construction [12]. On the other hand, the productive function caused by "investment impulse" promotes local economic growth. After the Chinese economy enters the transitional period, the proportion of local governments used for productive direct investment decreases, and the proportion of investment for achieving significant benefits increases, and gradually, it has become an important means for local governments to develop regional economies [13]. As known, enterprise is regarded an agglomeration channel and carrier of production factors, therefore, the establishment of new enterprises or the expansion of existing enterprises will further promote the growth of various factors [14], relevant governments will perform large scale industrial land transfer and low price agreements to attract foreign investment and promote the development of local industries; while the way of "bidding, auction, listing" is to transfer limited commercial and residential land at higher prices, under such method, the benefits obtained can cross-subsidize profit vacancies caused by low-cost transfer of industrial land, so as to strengthen local investment attraction ability and drive Local economic growth $[15,16]$. In a word, the public and production functions of land finance have jointly promoted regional economic development.

Most of the existing literature believe that land finance promotes local economic growth, but its research is also mostly limited to qualitative analysis. The literature that uses empirical methods to analyze the relationship between the two is very scarce, and only through empirical analysis can objectively measure the "credits and discredits" of land finance, and make reasonable analysis and choices on the trade-off of land finance. As the behavior of local government, research on land finance must start with local governments in order to obtain more objective and accurate conclusions. At the same time, local economic growth has obvious dynamic continuity. The static analysis of the relationship between the 
two will inevitably lead to endogenous effect, resulting in inaccurate results. To this end, this paper uses 265 prefecture-level cities from 2003-2017 in China as samples, and SYS-GMM of dynamic panel data to conduct empirical analysis to study the relationship between land finance and economic growth; meanwhile, on this basis, this paper elaborates the importance of land finance for China's economic development at the current stage, and puts forward relevant policy recommendations for the transformation of land finance.

\section{Models and Data}

\subsection{Model Construction}

\subsubsection{Basic Model}

Based on the existing literature and the needs of this study, the following panel regression model is established. The explained variable is the real GDP growth rate (GDP_GROWTH), which is represented by the real GDP growth rate of the cities in various regions in China during 2003-2017 (gained by deflation taking 2003 as base period).

$$
\begin{aligned}
& G D P P_{-} G R O W T H_{\mathrm{it}}=\alpha_{0}+\alpha_{1} L F R E X P_{\mathrm{it}}+\alpha_{2} F S R \text { it }+\alpha_{3} F A I I_{-} \text {GROWTHit }_{+} \\
& \alpha_{4} G D P P_{-} S I_{\text {it }}+\alpha 5 F D I{ }_{-} G D P \text { it }+\beta \text { L.GDP_GROWTHit } 1+\varepsilon_{i \mathrm{t}}
\end{aligned}
$$

In this model, land finance (LFREXP) is the core explanatory variable, and the broad land finance includes more than 20 kinds of rents, taxes, and fees, taking into account the availability of relevant data and the small proportion of other taxes and fees, this paper selects land transfer in various cities throughout the years as revenue of land finance. Since the dependence on the local finance and the development model of each region are affected by the fiscal expenditure in the region, this paper selects the ratio of the land transfer fee to the expenditure of the local fiscal general budget as the measurement indicator of the land finance. According to the existing literature, this paper controls the impact of the following variables on economic growth.

1) Financial self-sufficiency rate (FSR). Scholars at home and abroad generally believe that the mismatch between local government financial power and authority is an institutional incentive that has led to the rapid development of China's land finance in recent years after the tax-sharing reform. Therefore, this paper selects financial self-sufficiency as a control variable to add into the model to reflect the influence of local government's financial self-sufficiency capacity on economic growth. The self-sufficiency rate of finance is measured by the proportion of local government budget revenues within the budgetary expenditures.

2) Fixed assets investment growth rate (FAI_GROWTH). Under the current performance appraisal system in China, local governments will make large-scale investments to boost local economic growth in order to win in Promotion Tournament. This paper adds the growth rate of investment in fixed assets to the model to analyze the impact of local government investment on local economic growth.

3) Industrialization level (GDPP_SI). Industrialization has made a great contribution to China's economic growth. This paper represents the industrialization level by the proportion of the output value of the second industry to GDP to analyze the impact of the level of industrialization on economic growth.

4) Foreign direct investment (FDI_GDP). China's opening to the outside world has attracted a large number of foreign-funded enterprises to settle in, and has made significant contributions to China's economic growth. This paper selects the amount of local actual foreign investment measured in RMB as a percentage of local real GDP for that year. The subscripted i means region, t means year and $\varepsilon_{\text {it }}$ is random disturbance.

\subsubsection{Dynamic Model}

In order to strengthen the control of missing variables and reverse causality that affect economic growth, this paper adds the lag phase of the dependent variable to the model to build a dynamic panel data regression model:

The lagged terms of the economic growth rate appear on the right side of the equation and may be related to the random disturbance of the model. In addition, from the existing literature, there may be a mutual causal relationship between economic growth and land finance, which leads to the endogenous problem of explanatory variables. In order to solve this problem, using the generalized moment estimation or tool variable method to estimate the equation are commonly used methods in existing research. Although instrumental variable method can solve endogenous problems to a certain extent, it can easily cause omission of other variables in the model, leading to false regression. To this end, the two-step robustness estimation suggested by Windmeijer (2005) is adopted in this paper. Considering that the effectiveness of instrumental variables largely determines the system GMM estimator, this paper uses AR test and Sargen test to identify from them. In the test, the original hypothesis is that the original instrument variables are jointly valid, and the residual items are allowed to have a first-order sequence correlation, while no second-order sequence correlation is allowed.

\subsection{Model Interpretation}

This paper uses the panel data of 265 prefecture-level cities in 2003-2017 (in which Jiangxi, Xinjiang Uygur Autonomous Region, Tibet and small number of prefectural cities in other provinces are excluded because of lack of data) to analyze the role of land finance to local economic growth. The 2003-2017 China Land and Resources Statistics Yearbook provides data support for land transfer payments in this paper. The relevant data for other years are from the China City Statistical Yearbook and China Statistical Yearbook. All data are price data of that year. This article converts it into 2003 constant price data based on the 2003-2017 consumer price index. The corresponding descriptive statistics are shown in Table 1. 
Table 1. Statistical description of variables.

\begin{tabular}{llllll}
\hline Indexes & Minimum value & Maximum value & Mean value & Standard deviation & Observation value \\
\hline Real GDP growth rate & -3.4 & 37.69 & 13.8435 & 3.2199 & 2385 \\
Land finance & 0 & 291.623 & 30.7841 & 31.4494 & 2385 \\
Industrialization level & 9 & 85.92 & 48.6826 & 11.3387 & 2385 \\
Financial self-suffciency rate & -5.6943 & 125.6947 & 49.445 & 22.5736 & 2385 \\
FDI & 0 & 87.2789 & 2.4342 & 3.9489 & 2385 \\
Growth rate of fixed assets investment & 71.832 & 148.7218 & 26.2074 & 18.046 & 2385 \\
\hline
\end{tabular}

\section{Empirical Results}

The coefficient of local real GDP growth lags is highly significant at the $1 \%$ significance level, indicating that the level of economic growth has autocorrelation, and the greater impact of the previous period of growth also indicates the necessity of constructing a dynamic panel model. AR (1) rejects the null hypothesis and AR (2) accepts the original hypothesis, its statistics are not significant at the significant level of $5 \%$, indicating that the original hypothesis of no second-order sequence correlation is tenable, that is, the model setting is desirable. At the same time, the Sargan test statistic is not significant, it rejects the existence of over-identification of the original hypothesis, and the tool variable selection is effective.

The basic idea of the system GMM is to add the horizontal formula as a supplement to the estimation equation, and the final estimation is the horizontal equation and the difference equation. At this time, the horizontal equation dependent lag term ( $L . G D P$ GROWTHit-1) uses its differential lag term ( $L . G D P \_G R \bar{O} W T H_{\text {it }-1)}$ ) as the instrumental variable. For the system GMM estimation, the horizontal equation and the difference equation are integrated, and a set of lagging differential variables is also used as a tool for the corresponding variable of the horizontal equation. In general, better quality finite samples can have better control of endogenousness.

\subsection{National Level Data}

Table 2. Land finance and local economic growth: Regression results of panel data of 265 prefecture-level cities across the country.

\begin{tabular}{llll}
\hline Explanatory variables & Model 1 GMM & Model 2 FE & Model 3 OLS \\
\hline L GDP growth & $0.375 * * *(0.0369)$ & $0.146 * * *(0.0212)$ & $0.369 * * *(0.0178)$ \\
lfrexp & $0.0650 * * *(0.00871)$ & $0.00477(0.00309)$ & $0.00439 *(0.00233)$ \\
fsr & $-0.0520 * * *(0.00904)$ & $0.00650(0.00838)$ & $-0.00935 * * *(0.00350)$ \\
Fai growth & $0.0557 * * *(0.00670)$ & $0.0483 * *(0.00416)$ & $0.0512 * * *(0.00405)$ \\
Fdi.gdp & $0.213 * * *(0.0644)$ & $0.0205(0.0184)$ & $0.0333 * *(0.0163)$ \\
Gdpp_si & $0.0468 * * *(0.00867)$ & $0.0731 * *(0.00963)$ & $0.0344 * * *(0.00571)$ \\
constant & $5.187 * * *(0.763)$ & $6.774 * * *(0.706)$ & $5.877 * * *(0.342)$ \\
Oberservations & 2,120 & 2,120 & 2,120 \\
Number of cityid & 265 & 265 & 265 \\
\hline
\end{tabular}

Note: FE is fixed effect estimate, OLS is mixed estimate, GMM is system GMM estimate, ***, **, and * are significant at the $1 \%$, $5 \%$, and $10 \%$ levels respectively, and $t$ in parentheses is the statistics.

From Table 2, it can be seen that the core explanatory variable LFREXP is in significant positive correlation with local economic growth at the $1 \%$ level, indicating that land finance still plays an important role in promoting local economic development in the current stage of economic development in China. Bond (2002) found that when the model explanatory variable is the dependent variable's lagging term, the mixed estimator will cause estimators of the dependent variable lag term upward bias; while using the fixed effect model regression, it will cause estimate of dependent variable lagged terms downward bias. Based on this, the scientific lag estimate should be kept within the limits of both. From this paper, the estimated parameter of the first-order lag term (L.GDP_GROWTH) estimated by the fixed-effect model is 0.146 , and the estimated result of the mixed estimate is 0.396 , so the true coefficient should be between 0.146 and 0.396 . Judging from the regression results at the national level, the estimate of the first-order lagging term (L.GDP_GROWTH) of the economic growth rate estimated by the system GMM model is 0.375 , which is within the range.

In terms of control variables, the government's self-sufficiency ratio has a significant negative correlation with local economic growth. This further shows that the mismatch between the central government's financial power and authority makes local governments face financial pressure and will seek extrabudgetary income to invest. The level of opening to the outside world has a significant positive correlation with China's economic growth. This shows that after China's accession to the WTO, foreign investment has played a significant role in promoting China's economic development. In addition, the investment in fixed assets and the level of industrialization have positive effects on China's economic growth to varying degrees, and are highly significant at the $1 \%$ level of significance. 
Table 3. Land Finance and Local Economic Growth: GMM Regression Results of Panel Data of Regional Cities by Region.

\begin{tabular}{llll}
\hline \multirow{2}{*}{ Explanatory variables } & Model 1 & Model 2 & Model 3 \\
\cline { 2 - 4 } & GMM & FE & OLS \\
\hline L GDP growth & $0.375^{* * *}(0.0369)$ & $0.146^{* * *}(0.0212)$ & $0.369^{* * *}(0.0178)$ \\
ffrexp & $0.0650^{* * *}(0.00871)$ & $0.00477(0.00309)$ & $0.00439^{*}(0.00233)$ \\
fsr & $-0.0520^{* * *}(0.00904)$ & $0.00650(0.00838)$ & $-0.00935^{* * *}(0.00350)$ \\
Fai growth & $0.0557^{* * *}(0.00670)$ & $0.0483^{* * *}(0.00416)$ & $0.0512^{* * *}(0.00405)$ \\
Fdi.gdp & $0.213^{* * *}(0.0644)$ & $0.0205(0.0184)$ & $0.0333^{* *}(0.0163)$ \\
Gdpp_si & $0.0468^{* * *}(0.00867)$ & $0.0731^{* * *}(0.00963)$ & $0.0344^{* * *}(0.00571)$ \\
constant & $5.187^{* * *}(0.763)$ & $6.774^{* * *}(0.706)$ & $5.877^{* * *}(0.342)$ \\
Oberservations & 2,120 & 2,120 & 2,120 \\
Number of cityid & 265 & 265 & 265 \\
AR (1) & $0.000(-7.17)$ & $0.000(-4.18)$ & $0.000(-4.95)$ \\
AR (2) & $0.209(1.26)$ & $0.099(1.65)$ & $0.262(-1.12)$ \\
Sargen Test & $0.164(35.199)$ & $0.189(34.827)$ & $0.127(36.199)$ \\
\hline
\end{tabular}

Note: FE is a fixed effect estimate, OLS is a mixed estimate, GMM is a systematic GMM estimate, ${ }^{* * *}, * *$, and * are significant at the $1 \%, 5 \%$, and $10 \%$ levels, respectively, and and $t$ in parentheses is statistics. AR (1) and AR (2) represent autocorrelation test results. Sargen is the result of an over-identification test. ***, $* *$, and * are significant at the $1 \%, 5 \%$, and $10 \%$ levels, respectively, and $t$ in in parentheses is statistics.

\subsection{Regional Data}

Considering that some areas with missing data are eliminated during data collection in this paper, the number of excluded prefecture level cities in the western region is large, which leads to a smaller sample size in the western region. And, the prefecture-level cities in the Western region are mainly areas with similar levels of economic development in central China, such as Sichuan, Shaanxi, and Chongqing. Therefore, this paper combines the samples of the central and western regions for analysis.

Judging from the regression results by region, the land fiscal indicators in the eastern region have a significant positive correlation with local economic growth and their coefficient values are lower than the national level, while land finance in the central and western regions has a significant positive correlation with local economic growth and is much higher than that in the eastern region, this paper believes that it can be explained from the following aspect. First of all, in 2003, the Central Government began to implement land supply policies that are conducive to the development of the central and western regions in view of the relatively poor land conditions in the central and western regions of China. Correspondingly, it reduced the amount of land supply in the east and caused the price of land in the eastern region to rise. With the increase of land supply in the central and western regions and relatively low land prices, local governments have the advantage of attracting investment. Secondly, due to the lower level of economic development in the central and western regions, the slower urbanization process, and the smaller amount of per capita GDP, compared with the eastern region, the effect of land transfer fees on promoting economic growth is more pronounced; In addition, due to the fact that the role of investment in promoting economic growth has not achieved practical results in the central and western regions, under this background, the land can play a better energy efficiency in investment, and its marginal efficiency is higher, then its impact on economic growth is greater positive. Thirdly, since the urbanization process and per capita GDP have reached a relatively advanced level in some eastern regions, compared to the central and western regions, the role of the land finance of the eastern region in promoting economic growth is limited, and more and more land finance has been used in public services such as medical care, health and education. Based on this, the role of land finance in the eastern region of China in terms of economic growth is less than that in the central and western regions.

In terms of control variables, the financial self-sufficiency rate of the local governments in the eastern region is negatively correlated with the economic growth at a significant level of $1 \%$, this shows that there is a strong investment impulse in the local governments of the eastern region, that is, the higher the fiscal expenditure within the local government budget, the greater the promotion to local economic growth. Foreign investment is very significant for the economic development of the eastern region. It shows that local governments have the advantage of attracting investment in the eastern part of the country, which promotes local economic growth through investment promotion. The central and western regions are at a disadvantage in attracting investment competition, and foreign investment is not significant for the economic development in the central and western regions. In addition, the investment in fixed assets and the level of industrialization have positive effects on economic growth in eastern and western regions, and are highly significant at the level of $1 \%$, indicating that government investment is still significant to the economic growth of China.

\section{Conclusions and Policy Recommendations}

This paper uses 265 prefecture-level cities from 2003-2016 in China as samples and SYS-GMM method to conduct empirical analysis, and study the relationship between land finance and economic growth. The results show that: Land finance has a significant role in promoting economic growth in various cities. The results of the sub-regional studies indicate that there are significant regional differences in 
regional economic growth for land finance, and a greater impact on the central and western regions than that in east regions. Based on the above analysis, this paper believes that the land finance issue does not lie in the land finance itself, but in deeper flaws and drawbacks of China's systems and policies. In China's current economic development environment, land finance has a solid and objective basis for its existence, but it must be promoted for transformation.

\subsection{Theoretical Foundation of the Existence of Land Finance}

1) China is a country with public ownership as its main body and implements socialist market economy system, and insists on the public ownership of land. Therefore, it is a reasonable economic activity for local governments to use their participation in social and economic activities and gain returns. Judging from the current situation of China's economic development, China has entered a new normal economy and the economic growth rate has slowed down. At the same time, according to the understanding of China's industrial optimization and transformation, China is still in the stage of promoting urbanization as its key objective. In the coming period, land finance will also be significant in promoting the development of urbanization.

2) The value of China's land and resources is huge, especially in the central and western regions, there is still a lot of space for exploration. This part of resources must be firmly possessed by government. The urbanization and industrialization of the central and western regions lag far behind the eastern region, and relying solely on central transfer payments for fixed-asset investment and industrialization to promote economic development appears to be "simple and weak." Under the general trend of industrial transfer, the central and western regions have ushered in good development opportunities, plentiful land transfers can not only obtain land fiscal revenue, but also promote the process of local industrialization and urbanization, thus stimulating local economic development.

3) As China is currently in the context of structural tax cuts and stabilizing macro tax burdens, it is impractical to add a new tax type to adapt it to the land transfer payment system. Therefore, from the perspective of safeguarding China's macroeconomic stability and healthy fiscal revenue, land finance should not be interrupted in a short period of time. Although local governments have the urge to sell land in order to promote local economic growth and even some officials have the bad purpose of broadening their political future, it is only one aspect of the problem. To provide local people with an economic source of social welfare, land finance is indispensable.

\subsection{Paths for Land Finance Transformation}

1) Land fiscal revenue transformation. The high proportion of land transfer fees in land revenue is a major cause of terribly distorting land finance in China. From the American experience, the main financial pillar of local governments should be tax-based, and property tax must account for over $50 \%$ of local government tax revenue. At the same time, the property tax has become a fairly substantial and stable tax revenue for local governments, and urges the local leadership to focus their construction efforts on improving public service levels and enhancing their ability to attract investment. In view of this, local governments should work hard to improve the relevant systems, levy land related taxes and fees reasonably from taxpayers, and reduce the proportion of land transfer income and land credit as collateral. The national taxation department should supplement the relevant guidelines for land value-added tax and other taxes, and continue to adopt the method of piloting in some areas groping for the implementation of new taxes such as real estate taxes, and strive to increase the share of taxation of prefectural-level governments so as to reduce, so as to reduce the dependence of local governments on land transfer revenue.

2) Land fiscal expenditure transformation. The production and public functions of land finance have been seriously asymmetric in the incentive model of the GDP promotion championship promoted by the provincial and municipal governments. They have divorced from the public finance function and used the land finance main revenue in infrastructure construction, investment and investment and land melting to promote regional economy, which is of serious bias in production expenditure. This kind of expenditure bias leads to a serious shortage of public livelihood projects and social welfare expenditures, and it is also one of the main reasons for expanding the income gap between urban and rural areas. In this regard, relevant government departments can implement fund-based management of land revenues and include them in the special revenue system of the central government so that the state can afford some of the social security, agricultural science and technology, and education expenses that were originally incurred by local governments.

3) Government functions transformation. As China's economy has entered the new normal, the government must not only play its role of macro-control and market supervision, but also improve and promote public service functions and social management functions, change the political promotion mechanism with GDP as the center, and increase livelihood indicator in the evaluation index system of cadres. It is required to distinguish the boundaries of the government, market, and society rationally, and use PPP or other methods to regulate and control public infrastructure projects and service facilities that can assume sole responsibility for their own profits or losses, thereby alleviating investment pressures and related costs faced by the government, achieving the goal of changing from an omnipotent government to a service-oriented government, and reversing the finance role of land finance from root cause.

\section{References}

[1] Lu Wei, Xu Hongwei: Economic Impact of Land Finance and Its Follow-up Risk Response, Comparative Economic and Social Systems, 06, 2012, page 78-86. 
[2] Sun Xiulin and Zhou Feizhou: Land finance and tax sharing system: an empirical explanation, Social Sciences in China, 04, 2017, page40-59.

[3] Lei Xiaoyu, Gong Liutang; Industrialization and urbanization based on land transfer. Management World, 09, 2014, page $29-41$.

[4] Zhang ping, Liu Xiahui; Urbanization, fiscal expansion and economic growth. Economic Research Journal, 11, 2011, page $4-20$.

[5] Zhang Liangyue; Property tax, tax source substitution and farmland protection. Finance\&Economics, 06, 2009, page $110-116$.

[6] Tao Ran, Yuan Fei, Cao Guangzhong; Regional competition, land transfer and local fiscal effects. The Journal of World Economy, 10, 2007, page 15-27.

[7] Huang Xiaohu; The trend of China's land system and land policy. China Taxation, 04, 2012, page 58-59.

[8] Song Xiaoning, Yang Zhiguo; Agricultural land acquisition, fiscal decentralization and manufacturing development. Comparative Economic \& Social Systems, 06, 2008, page 102-106.

[9] Li Wei, Hong Guozhi, and Huang Liangxiong: The Enigma of China's Land Financial Growth: Tax System Reform and Strategic Tactics of Land Financial Growth, Economics (quarterly), 04, 2016, page 1141-1160.
[10] Cao Guangzhong, Yuan Fei, and Tao Ran:Land finance, the evolution of industrial structure and the excessive growth of taxes: an analysis perspective of China's "mystery of tax growth", China Industrial Economics, 12, 2007, page13-21.

[11] Zou Wei, Liu Hongyi: Is land finance "drinking poison to quench thirst"? Based on the spatio-temporal dynamic spatial panel analysis of prefecture level cities in China, Economist, 09, 2015, page 21-32.

[12] Zhang Li, Gao Yuanhua, and Xu Xianxiang:Land transfer under the conspiracy of government and enterprise, Management World, 12, 2017, page43-51.

[13] Zou Xiuqing: Study on the relationship between land finance and economic growth in China -- the hypothesis of land finance Cruz Nez curve hypothesis and panel data inspection, China Land Science, 05, 2013, page 14-19.

[14] Lei Xiaoyu, Gong Liutang: Industrialization and urbanization based on land transfer, Management World, 09, 2014, page 29-41.

[15] Tao Ran, Yuan Fei, and Cao Guangzhong: Regional Competition, Land Transfer and Local Fiscal Effects: An Analysis Based on Panel Data of China's Prefectural Cities from 1999-2003, World Economics, 10, 2017, page 15-27.

[16] Wang Xianbin, Zhang Li, and Xu Xianxiang:Land transfer, infrastructure investment and local economic growth of local governments, China Industrial Economics, 07, 2014, page 31-43. 